\title{
Laparoscopic Total Colectomy in Colonic Inertia
}

\section{Marllus Braga Soares ${ }^{1, *}$, João de Aguiar Pupo-Neto², Isis Alves Galvão Soares ${ }^{3}$, Thais Viana ${ }^{4}$, Daniel Antonio Tavares ${ }^{4}$, Natália Viana ${ }^{4}$, and Hilton Carlos Chicon Costalonga ${ }^{4}$}

${ }^{1}$ Surgeon-in-chief, Department of Colorectal Surgery, Hospital São José do Avaí, Rio de Janeiro, Brazil

${ }^{2}$ Surgeon-in-chief, Department of Colorectal Surgery, Hospital Universitário Clementino Fraga Filho (HUCFF), Rio de Janeiro, Brazil

${ }^{3}$ Nutrologist-in-chief, Department of Neurology, Hospital São José do Avaí, Rio de Janeiro, Brazil

${ }^{4}$ Medical student, Universidade Nova Iguaçu, Intern of Colorectal Surgery Department, Hospital São José does Avaí, Rio de Janeiro, Brazil

*Corresponding author: Marllus Braga Soares, Surgeon-in-chief, Department of Colorectal Surgery, Hospital São José do Avaí, Rio de Janeiro, Brazil, Tel: (+55) 22 38249200; E-mail: marllusbsoares@hotmail.com; soaresmarllus@gmail.com

Received: 03 Oct, 2019 | Accepted: 28 Oct, 2019 | Published: 04 Nov, 2019

Citation: Soares MB, Pupo-Neto JA, Soares IAG, Viana T, Tavares DA, et al. (2019) Laparoscopic Total Colectomy in Colonic Inertia. J Surg Open Access 5(6): dx.doi.org/10.16966/2470-0991.197

Copyright: (C) 2019 Soares MB, et al. This is an open-access article distributed under the terms of the Creative Commons Attribution License, which permits unrestricted use, distribution, and reproduction in any medium, provided the original author and source are credited.

\begin{abstract}
Chronic constipation brings a great impact on quality of life. Colonic inertia is a rarely and extreme degree of constipation with difficult clinical treatment and often frustrating to the patient. Surgical treatment for colonic inertia is an interesting alternative and has a high success rate. We present the case of a patient with colonic inertia who underwent surgical treatment with total colectomy with ileorectal anastomosis by laparoscopy.
\end{abstract}

Keywords: Constipation; Colonic inertia; Total colectomy with ileorectal anastomosis

\section{Introduction}

Colonic inertia is a condition that prompts slow colonic transit along the colon, engendering chronic and serious colonic constipation and is a diagnosis of exclusion. It corresponds to approximately $3 \%$ of chronic constipation cases and affects chiefly young women (2030 years-old) [1]. So far, it has not a well-defined physiopathology and is diagnosed after complete investigation into other causes of colonic constipation. Its clinical case is characterized by serious constipation; with high grades of Wexner score of constipation [2], in which it can occur as few as one or two defecations monthly, abdominal distention, nausea and abdominal pain. The diagnosis is done after deep investigation on secondary causes of constipation, such as: dietary modifications, evacuation routine, medication of chronic usage, obstructive causes, mega colon, pelvic floor disorders, endocrine-metabolic causes, neurological and psychiatric illness $[3,4]$. The main diagnostic tests used was the anorectal manometry (functional study of the anus and rectum), defecography (evaluates morphological changes of the pelvis and the anorectal segment, thus excluding the syndrome of outlet obstruction) and the colonic transit time radiography, in which we can confirm that there is a significant and pathological decrease in the number of colonic contractions.

\section{Case Report}

A 68-year-old woman, white, hypertensive, diabetic with chronic colon constipation for approximately 20 years reporting severe and recurring abdominal pain and abdominal distension. The patient fulfilled the Roma criteria for constipation given that she presented straining during defecation, dark and lumpy stools and sensation of incomplete defecation in more than $25 \%$ of evacuations, in addiction to evacuate, in average, once in 14 days. She made continuous use of laxative medication, suppositories, fleet enema and manual extraction of stool for more than 10 years. The Wexner score of constipation was used to classify the severity of constipation, with a result of 28 (severe constipation). After investigation into secondary causes, not being identified other apparent causes for the case, the patient was submitted to the following complementary specific exams:

- Colonoscopy: presenting normal in all colonic extension.

- Colonic transit time: retention of twenty of the twenty-four radiopaque markers after the fifth day (Figure 1).

- Anal manometry: internal sphincter hypotonia with preserved anorectal inhibitory reflex. Balloon expulsion test was normal.

- Defecography: physiological normality in the defecation process.

After exams analysis, it was confirmed the diagnostic of colonic inertia and decided by the surgical treatment due to failure of conservative treatment after long time. We opted to realize total colectomy with ileorectal anastomosis by video laparoscopy. The surgery was performed with the patient in Lloyd-Davies position. The surgery was carried out through the insertion of 5 trocars in the following positions: $10 \mathrm{~mm}$ umbilical port for optic view, 12 $\mathrm{mm}$ in the right iliac fossa and three $5 \mathrm{~mm}$ in the right flank region, left iliac fossa and left flank region (Figure 2). Surgery started with the medial mobilization of the right side colon and also the hepatic flexure. Sequentially, it was held medial mobilization of the left side colon and the splenic flexure. Because of technical standardization, 


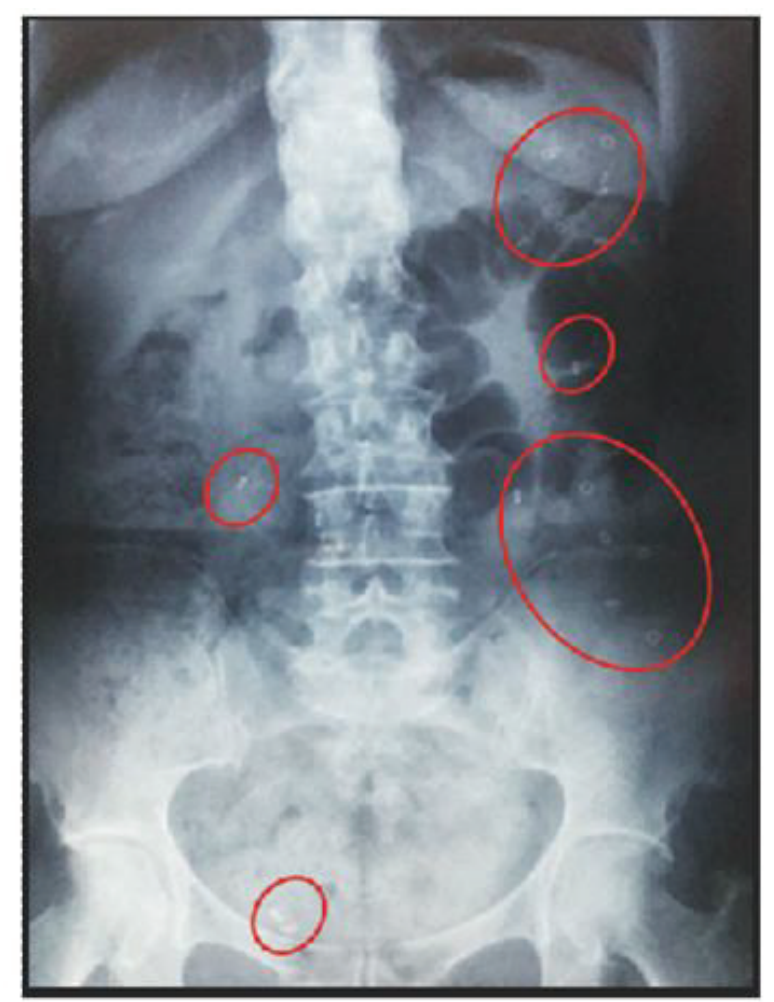

Figure 1: Colonic transit time. Abdominal radiograph after ingestion of 24 radiopaque markers after the $5^{\text {th }}$ day, the patient still had 20 markers.

the transverse colon was approached at the final step of the dissection. All vascular pedicles were handled near to the colon. The left colonic segment section was held in colorectal transition with two purple loads laparoscopic $45 \mathrm{~mm}$ stapler. Colonic right section was held 10 $\mathrm{cm}$ from the ileocecal valve into the ileum. Surgical specimen was externalized through the enlargement of umbilical $10 \mathrm{~mm}$ trocar. Ileorectal anastomosis was performed with circular $31 \mathrm{~mm}$ with a thickness of $4.8 \mathrm{~mm}$ stapler transanal introduced. Total operative time was 106 minutes. The first 24 hours postoperative period was conducted in an intensive care unit. The oral test diet was started on the first day after surgery. Patient developed gastro paresis 48 hours after the start of oral test diet, the situation was reversed with pharmacological treatment and zero oral diet. Patient was discharged on the ninth postoperative day in a good general condition without other complications. The pathological examination showed no microscopic lesions on surgical specimen. The patients currently in ambulatory follow up after one year of surgery, keeping one to two evacuations daily with normal consistency, without abdominal pain, diarrhea or use of medications for constipation. The new Wexner score of constipation was zero.

\section{Discussion}

Surgical treatment for colonic inertia is an interesting alternative and has a high success rate [5-8]. The most widely used technique is the total colectomy with ileorectal anastomosis, having a success rate reported in the literature around $90 \%$ and less than $1 \%$ operative mortality [1]. In the case set, we opted for the anastomosis of the ileum with superior rectus (at the promontory height), to be safe

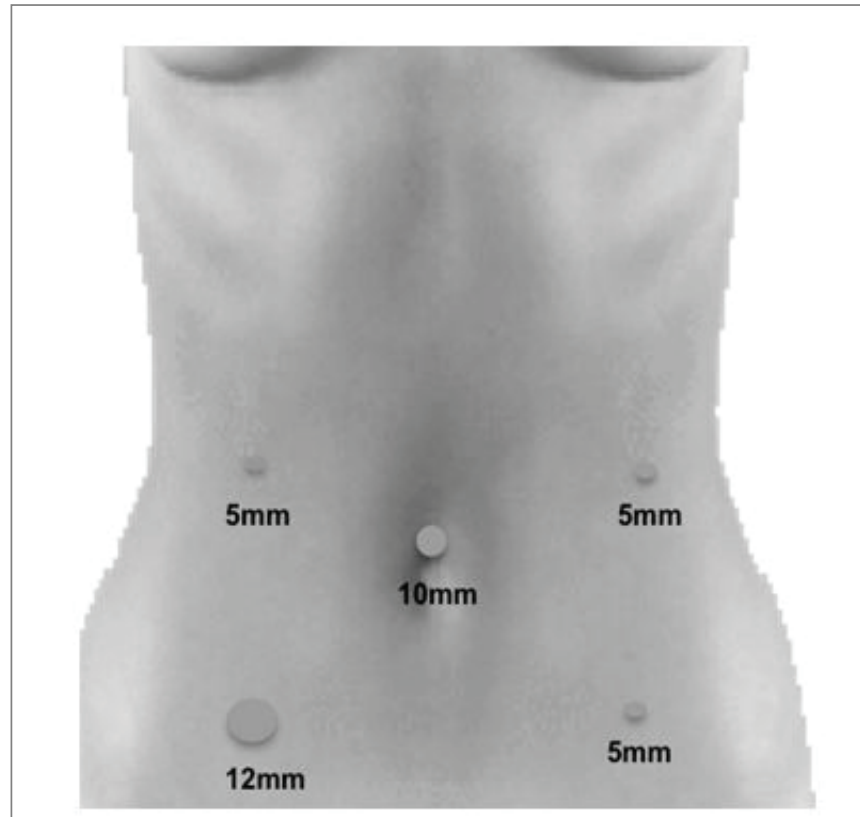

Figure 2: Trocars arrangement.

technique with lower risks associated with the mobilization of the rectum, avoiding pelvic dissection and possible nerve damage of sympathetic or parasympathetic origin. The colonic transit time is a "key" for diagnosis of colonic inertia, where more than $80 \%$ of radiopaque markers remain in colon after the fifth day of ingestion. Colonic inertia keeps the markers distributed diffusely throughout the colon, which does not occur in the obstructed defecation syndrome, where the radiopaque markers are concentrated in the following colon and/or distal rectal. This test must be supplemented with defecography and anorectal manometry for the obstructed defecation syndrome evaluation (rectocele or anismus). In the reported case, radiopaque markers were concentrated mostly in the left colon segment, with the possibility of performing left hemicolectomy. It was opted for the total colectomy by the fact that segmental colectomy for treatment of colonic inertia have a high rate of surgical failure, with early or late recurrence of constipation [9-11]. The use of laparoscopy proved to be safe without adding excessive surgical time for the procedure and/or technical difficulties.

\section{Conclusion}

In cases of clinic treatment failure, patients with colonic inertia benefits from surgical approach. Several studies have demonstrated that total colectomy with ileorectal anastomosis is the procedure of choice for colonic inertia. Laparoscopic techniques add the benefits of minimally invasive surgery to the procedure. Additional prospective studies are needed to reveal the true impact of surgery on quality of life of patients.

\section{References}

1. McCoy JA, Beck DE (2012) Surgical Management of Colonic Inertia. Clin Colon Rectal Surg 25: 20-23.

2. Jorge JM, Wexner SD (1993) Etiology and management of fecal incontinence. Dis Colon Rectum 36: 77-97. 
3. Frattini JC, Nogueras JJ (2008) Slow transit constipation: a review of a colonic functional disorder. Clin Colon Rectal Surg 21: 146-152.

4. Lembo A, Camilleri M (2003) Chronic Constipation. N Engl J Med 349: 1360-1368.

5. Sonnenberg A, Koch TR (1989) Epidemiology of constipation in the United States. Dis Colon Rectum 32: 1-8.

6. Knowles CH, Scott SM, Rayner C, Glia A, Lindberg G, et al. (2003) Idiopathic slow-transit constipation: an almost exclusively female disorder. Dis Colon Rectum 46: 1716-1717.

7. Nyam DC, Pemberton JH, Ilstrup DM, Rath DM (1997) Long-term results of surgery for chronic constipation. Dis Colon Rectum 40: 273-279.
8. Preston DM, Hawley PR, Lennard-Jones JE, Todd IP (1984) Results of colectomy for severe idiopathic constipation in women (Arbuthnot Lane's disease). Br J Surg 71: 547-552.

9. Bernini A, Madoff RD, Lowry AC, Spencer MP, Gemlo BT, et al. (1998) Should patients with combined colonic inertia and nonrelaxing pelvic floor undergo subtotal colectomy? Dis Colon Rectum 41: 1363-1366

10. You YT, Wang JY, Changchien CR, Chen JS, Hsu KC, et al. (1998) Segmental Colectomy in the management of colonic inertia. Am Surg 64: 775-777.

11. FitzHarris GP, Garcia-Aguilar J, Parker SC, Bullard KM, Madoff RD, et al. (2003) Quality of life after subtotal colectomy for slow-transit constipation: both quality and quantity count. Dis Colon Rectum 46: 433-440. 